\title{
Seismic Hazard Assessment for the Tianshui Urban Area, Gansu Province, China
}

\author{
Zhenming Wang, ${ }^{1}$ David T. Butler III, ${ }^{2}$ Edward W. Woolery, ${ }^{2}$ and Lanmin Wang ${ }^{3}$ \\ ${ }^{1}$ Kentucky Geological Survey, University of Kentucky, Lexington, KY, USA \\ ${ }^{2}$ Department of Earth and Environmental Sciences, University of Kentucky, Lexington, KY, USA \\ ${ }^{3}$ Lanzhou Institute of Seismology, China Earthquake Administration, Gansu, Lanzhou, China \\ Correspondence should be addressed to Zhenming Wang, zmwang@uky.edu \\ Received 4 May 2012; Revised 27 July 2012; Accepted 14 August 2012 \\ Academic Editor: Vladimir G. Kossobokov
}

Copyright ( $\odot 2012$ Zhenming Wang et al. This is an open access article distributed under the Creative Commons Attribution License, which permits unrestricted use, distribution, and reproduction in any medium, provided the original work is properly cited.

\begin{abstract}
A scenario seismic hazard analysis was performed for the city of Tianshui. The scenario hazard analysis utilized the best available geologic and seismological information as well as composite source model (i.e., ground motion simulation) to derive ground motion hazards in terms of acceleration time histories, peak values (e.g., peak ground acceleration and peak ground velocity), and response spectra. This study confirms that Tianshui is facing significant seismic hazard, and certain mitigation measures, such as better seismic design for buildings and other structures, should be developed and implemented. This study shows that PGA of $0.3 \mathrm{~g}$ (equivalent to Chinese intensity VIII) should be considered for seismic design of general building and PGA of $0.4 \mathrm{~g}$ (equivalent to Chinese intensity IX) for seismic design of critical facility in Tianshui.
\end{abstract}

\section{Introduction}

The city of Tianshui, located in the southeastern part of the Gansu Province, China, is home to approximately 3.5 million citizens. Tianshui sits along the northeastern edge of the Qinghai-Tibetan Plateau (Figure 1). It is a center for manufacturing textiles, machinery, and appliances in northwestern China. Almost half a million people reside in its urban area. The interaction between the Eurasian and Indian Plates has been the driving mechanism for the high level of seismicity on the Qinghai-Tibetan Plateau and its foreland throughout the Cenozoic. During the late Eocene, the north moving Indian Plate collided with the Eurasian. This continued indentation caused crustal thickening and strike-slip faulting throughout the plateau (Figure 1). As shown in Figure 1, there are several major faults, including Haiyuan, East Kunlun, and West Qingling north boundary faults, surrounding Tianshui. Tianshui experienced more than 30 damaging earthquakes in the past 2,000 years. The earthquake that had the most significant impact (intensity $\mathrm{X}$ or greater) on the city of Tianshui is the M7.5 Tianshui earthquake of $734 \mathrm{AD}$ [1]. The most recent large earthquake affecting Tianshui was the May 12, 2008, $M_{W} 7.9$ Wenchuan earthquake. The 2008 Wenchuan earthquake caused damages (intensity VI/VII) in Tianshui. More than 80,000 human lives were lost as a result of the Wenchuan earthquake, with approximately U.S. $\$ 110$ billion damage [2]. Thus, the city of Tianshui is facing a significant seismic hazard and risk.

As shown by recent earthquakes, particularly the 2010 Haiti and Chile earthquakes and the 2011 New Zealand and Japan earthquakes, mitigations-better seismic design for buildings, bridges, and other infrastructure-are the most effective way to reduce seismic risk and avoid earthquake disasters. The Haiti earthquake (M7.0) resulted in more than 220,000 deaths from massive building collapse, whereas the Chile earthquake (M8.8) resulted in fewer than 200 deaths from building collapse. The low number of fatalities during the Chile earthquake was because of good seismic provisions for buildings. There was no major building collapse during the Japan earthquake (M9.0) because of stringent seismic provisions for buildings; the great loss of life was caused by the tsunami generated by the quake. Thus, it is vitally 


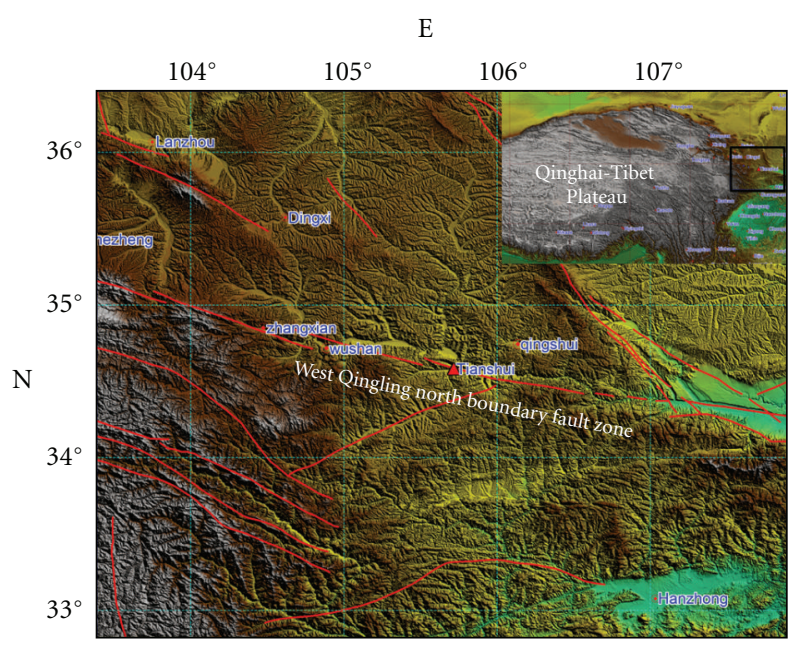

Figure 1: The study area and Holocene faults (red line).

important for the City of Tianshui to develop and implement stringent mitigation policies to reduce seismic risk and avoid earthquake disaster.

Development of mitigation policies, such as seismic provisions in building codes, is a complex process. For example, in the United States, the NEHRP Recommended Provisions for Seismic Regulations for New Buildings and Other Structures were developed through a complex process by the Building Seismic Safety Council [3]. As shown in Figure 2, the process for developing the NEHRP provisions started with the national seismic hazard maps, which were produced by the United States Geological Survey (USGS) [4]. Then a group of engineers, seismologists, and others, using the maps and engineering science, developed a set of recommendations, including design ground motions, for seismic regulations for new buildings and other structures. These recommendations were endorsed by the federal agencies and thus, became federal policy, with associated regulations, for seismic safety in the United States. The recommendations were also adopted by the state and local governments, as well as nongovernment organizations such as the International Building Code Council, resulting in the International Building Code [5]. Similarly, the Chinese national design peak ground acceleration map was produced by the China Earthquake Administration (CEA) [6]. The Italian national design ground motion maps were produced by the the Istituto Nazionale di Geofisica e Vulcanologia (INGV) [7].

As shown in Figure 2, development of policy for seismic hazard mitigation and risk reduction begins with seismic hazard assessment-seismic hazard map. In other words, seismic hazard assessment is the foundation of mitigation policy development. Thus, seismic hazard assessment is a critical element for the development of policy for seismic hazard mitigation and risk reduction.

1.1. Seismic Hazard Assessment. The main goal of seismic hazard assessment is to quantify ground motion at a site or in a region by earth scientists (e.g., geologists, geophysicists, and seismologists) or earth science agencies (e.g., USGS, CEA, and INGV) using scientific information obtained from instrumental, historical, and geologic observations. Seismic hazard assessment can be divided into two general categories: probabilistic and deterministic. The most commonly used probabilistic method is probabilistic seismic hazard analysis (PSHA), and deterministic method is deterministic seismic hazard analysis (DSHA). PSHA and DSHA use the same seismological and geologic information but define and calculate seismic hazard differently. In PSHA, seismic hazard is defined as the ground motion with an annual probability of exceedance (i.e., probability of exceedance in one year) and calculated from a mathematical model based on statistical relationships of earthquakes and ground motion [8]. In DSHA, seismic hazard is defined as the median or certain percentile (e.g., 84 percent) ground motion from a single earthquake or set of earthquakes and calculated from simple statistics of earthquakes and ground motion $[9,10]$. In other words, PSHA was intended to estimate the probability that ground motion exceeds a given level from all earthquakes, whereas DSHA estimates the ground motion from one or a set of scenario earthquake. PSHA emphasizes the probability and depends on the statistical models of earthquake, whereas DSHA emphasizes the ground motion and depends on the physical models of earthquake.

As pointed out by Hanks ([11], page 369), "PSHA is a creature of the engineering sciences, not the earth sciences, and most of its top practitioners come from engineering backgrounds. Relatively few earth scientists were involved in PSHA studies prior to the early 1980s." In other words, PSHA was resulted from the work by engineers in the 1970s, particularly Allin Cornell who "applied the mathematical rigor of probabilistic analysis" and Luis Esteva who "provided the underlying distributions (i.e., statistical relationships) of earthquake magnitudes, locations, and ground motion attenuation" (McGuire, 2008, page 337). PSHA is mathematically valid under a set of rigorous assumptions and underlying statistical relationships of earthquake magnitudes, locations, and ground motion attenuation. Recent studies [12-15]) have shown that those assumptions are not rigorous, even not valid in earthquake sciences, however. In addition, PSHA contains a mathematical error: equating a dimensionless quantity (i.e., the annual probability of exceedance; the probability of exceedance in one year) to a dimensional quantity (i.e., the annual frequency of exceedance or rate with unit of per year [1/yr.]) [13-15]. This mathematical error leads to the so-called ergodic assumption-"PSHA treats that spatial uncertainty of ground motions as an uncertainty over time at a single point" ([16], page 19) and the confusion between probability and frequency (per year) in PSHA [17]. Thus, PSHA is scientifically flawed, and results from PSHA are artifact. This explains why PSHA could derive the extreme ground motions of $11 \mathrm{~g} \mathrm{PGA}$ and $13 \mathrm{~m} / \mathrm{s}$ PGV at the Yucca Mountain nuclear waste repository site [18]. The PSHA analysts have become experts in probability theory, not experts in earth sciences, who could be better than "a monkey hitting keys on a typewriter" $[19,20]$. This can be seen in the latest examples in Musson [21, 22]. 


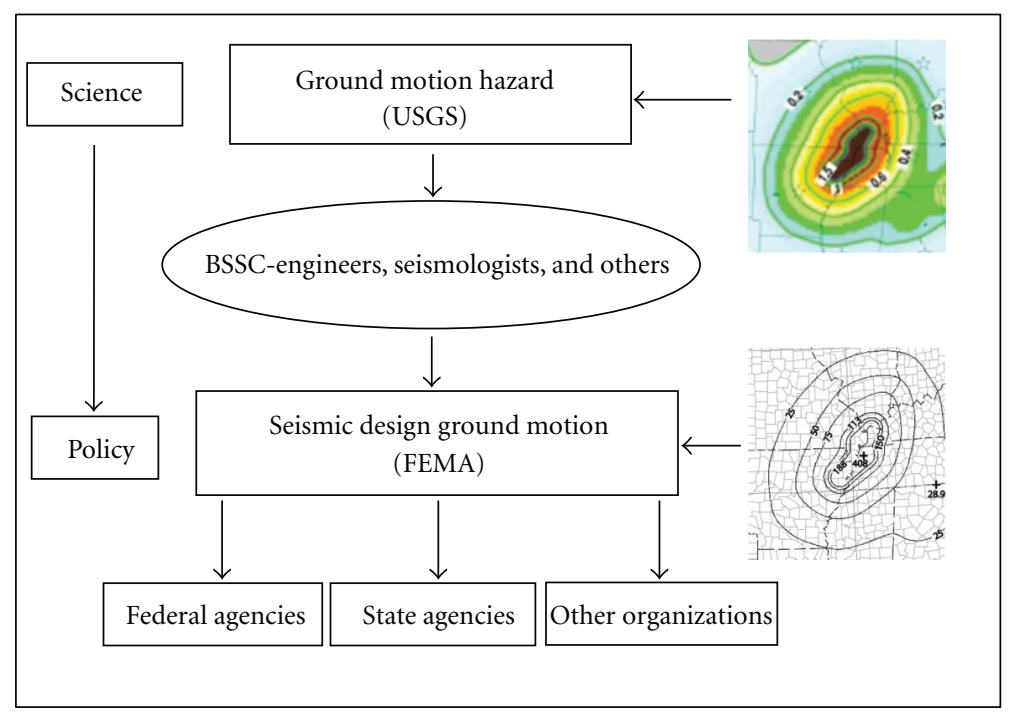

FIGURE 2: Development of the NEHRP recommended provisions: from seismic hazard map (science) to seismic design map (policy) in the United States.

Thus, the use of PSHA is problematic. As shown in Figure 3 , the design peak ground acceleration, which has a 10 percent probability of exceedance in 50 years and was derived from PSHA [6], in Wenchuan area is much less than the ground motions observed [23]. Other recent earthquakes, such as the 2009 L'Aquila earthquake (M6.3), the 2010 Haiti earthquake (M7.1), the 2011 Japan earthquake (M9.0), and the 2011 Christchurch earthquake, also showed that the ground motion with 10 percent probability of exceedance in 50 years was significantly underestimated [2427]. On the other hand, the ground motion hazards were also significantly overestimated by PSHA, including $11 \mathrm{~g}$ PGA at the Yucca Mountain, Nevada, nuclear waste repository site $[18,28]$, and $0.8 \mathrm{~g}$ PGA at the Paducah Gaseous Diffusion Plant near Paducah, Kentucky [15].

As mentioned earlier, DSHA determines the ground motion from a single or several scenario earthquakes that have maximum impact. It addresses the ground motion from individual (i.e., maximum magnitude, maximum probable, or maximum credible) earthquakes. Seismic hazard derived from DSHA has a clear physical and statistical meaning. Recent efforts in DSHA have focused on computer simulation for ground motion hazard quantification [29-33] called Neo-DSHA [30] or scenario hazard analysis. NeoDSHA or scenario hazard analysis has several advantages

(1) Ground motion derived has an easily understood physical and statistical meaning.

(2) The results are easily understood by earth scientists, engineers, and others.

(3) It utilizes ground motion simulation.

One of the drawbacks in traditional DSHA $[9,10]$ is that "frequency of occurrence is not explicitly taken into account" ([34], page 225). The temporal characteristic of earthquakes (i.e., recurrence interval or frequency and its associated uncertainty) is not addressed in traditional DSHA.

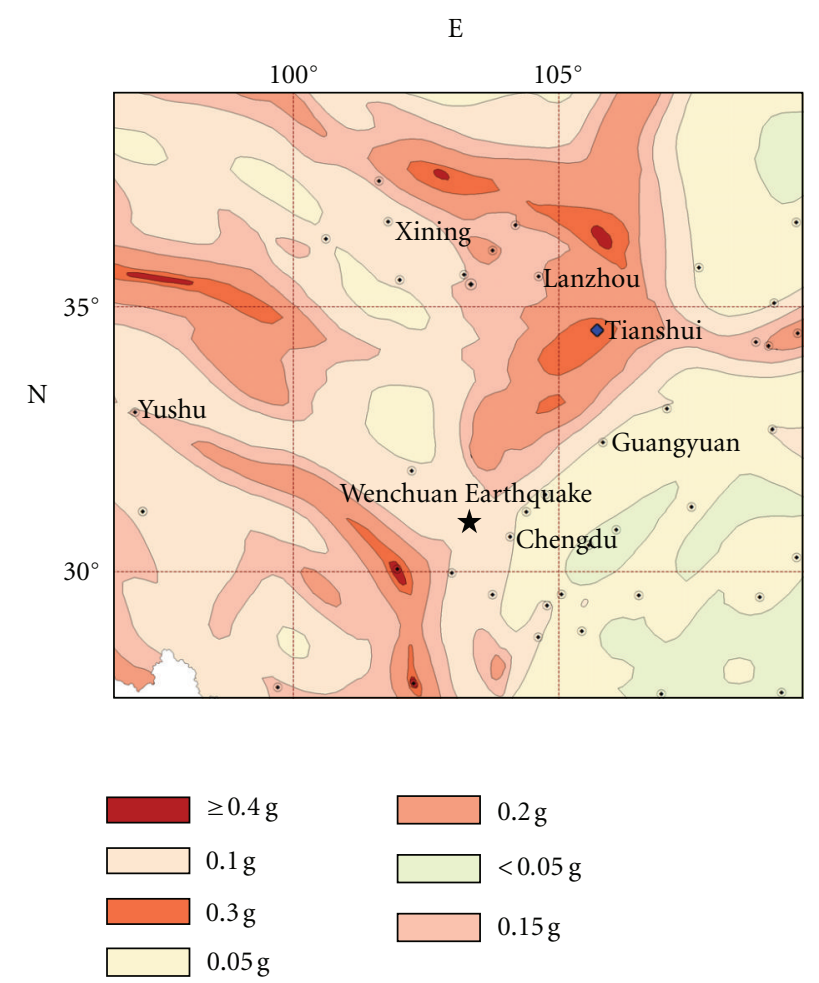

Figure 3: Chinese national design peak ground acceleration with 10 percent probability of exceedance in 50 years [6].

The temporal characteristic of earthquakes and resulting ground motions at a site is an integral part of seismic hazard and must be considered in engineering design and other policy considerations. As pointed out by Wang and others [35], a scenario earthquake can always be associated with a recurrence interval and its uncertainty. For example, the average recurrence interval of the New Madrid scenario 


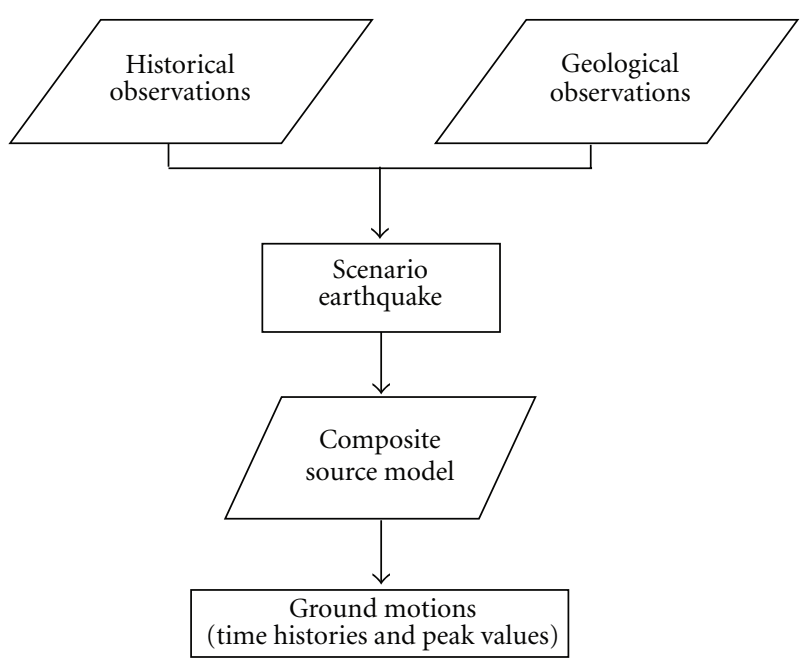

FigURE 4: Framework for determining ground motion hazard.

earthquake is about 500 to 1,000 years $[15,29,31]$. Thus, scenario hazard analysis also provides the temporal characteristics of ground motion.

Thus, DSHA is more appropriate for seismic hazard assessment. As shown in the NEHRP provisions [3], the design ground motion in coastal California is capped by the deterministic ground motion from the maximum considered earthquakes. The ground motion specified for bridge design in California is also determined by the deterministic ground motion from the maximum credible earthquake [36]. Thus, DSHA, not PSHA, was used to derive the design ground motions for the NEHRP provisions and the resulting building codes and other regulations for coastal California. In other words, the ground motion hazard maps produced from PSHA have never been used to develop the design ground motion for coastal California. Similarly, the design ground motions in Chile and Japan were not the probabilistic ground motion, but more a deterministic ones $[37,38]$.

\section{Methodology}

In this study, we applied a scenario seismic hazard analysis to determine the ground motion hazard in Tianshui area utilizing rich instrumental, historical, and geological data and advanced ground motion modeling. Figure 4 shows the framework of this study. First, the historical intensity data were analyzed to produce seismic hazard curves in terms of intensity versus exceedance frequency (per year), using an approach similar to that of Liu and others [39] and Xie and others [40]. In combination with the geological data, these hazard curves were used to determine scenario earthquakes. Then, the composite source model [41] was used to generate synthetic ground motion time histories on rock. Peak ground acceleration (PGA) and other ground motion parameters are extracted from the synthetic ground motion time histories. The time histories were also used to study site response in the Tianshui area [42].
2.1. Historical Intensity Data Analysis. Similar to the Gutenberg-Richter relationship, the intensities and their occurrence frequencies at a site can be derived from historical observations $[39,40,43]$. The intensities and their occurrence frequency are assumed to follow

$$
\log (f)=a-b \cdot I
$$

where $f$ is the frequency for intensity exceeding $I$, and $a$ and $b$ are constants. This approach was applied to determine the intensity hazard curves for Tianshui from historical observations.

An earthquake intensity database for Tianshui was constructed from earthquake catalogs by the State Seismological Bureau [44] and the China Earthquake Administration [45]. The State Seismological Bureau database is a compilation of 222 earthquakes with estimated magnitudes equal to or greater than M4.75 between $2300 \mathrm{BC}$ and $1911 \mathrm{AD}$. The China Earthquake Administration database contains 4,289 records of earthquake from 1912 to $1990 \mathrm{AD}$ having magnitudes of $M_{S} \geq 4.7$. Each earthquake record consists of a date, time, magnitude, latitude, and longitude for the inferred epicenter, as well as a general description of felt effects (i.e., casualties, injuries, buildings damaged, etc.). Most, but not all, of these records contain an isoseismal map noting the various intensity contours associated with each earthquake. These catalogs were queried for earthquakes with felt intensities in Tianshui between 0 and 1987 AD. The last year that an earthquake was felt in Tianshui was not 1987, but data sampling was controlled by the earthquake catalogs available. The search resulted in 32 reports of earthquakes of magnitude greater than M 4.7 between 128 and 1987 AD. Twenty-seven of these events occurred between 1501 and 1987. Of the 32 reports examined, all but nine contained isoseismal maps. For the nine earthquakes for which isoseismal maps were not available, the attenuation relationship defined by Wang and others [46] was used to calculate intensity as follows:

$$
I=2.429+1.488 M-1.391 \ln (R+11),
$$

where $I$ is intensity (Chinese scale), $M$ is magnitude, and $R$ is epicentral distance in $\mathrm{km}$.

2.2. Composite Source Model. Synthetic strong groundmotion has become an important component for seismic hazard assessment and engineering design and analysis. There are several approaches being used for generating synthetic ground motion, such as the stochastic point source [29, 47], stochastic finite source model [48], empirical Green's function [32, 49], composite source model [31, 41, 50], modal summation [30], and finite-difference [51, 52].

The composite source model [41] was chosen to synthetically characterize and estimate near-source strong motions. In the composite source model developed by Zeng and others [41], the source descriptions are based on the following assumptions: (1) the number of circular subevents with radius $R$ is specified by

$$
\frac{d N}{d(\ln R)}=p R^{-D},
$$


where $D$ is the fractal dimension, $N$ is the number of sub events, and $p$ is a constant of proportionality; and (2) the seismic moment of sub event with size $R$ satisfies the scaling relation of $M_{i}=C R_{i}^{3} \Delta \sigma$, where $C=16 / 7$ for a circular fault model, and $\Delta \sigma$ is a stress drop constant, independent of the sub event radius. The constraint of seismic moment conservation means that

$$
p=\frac{7 M^{t}}{16 \Delta \sigma} \frac{3-D}{R_{\max }^{3-D}-R_{\min }^{3-D}},
$$

where $M^{t}$ is the seismic moment of the main event, $R_{\max }$ is the largest sub event, and $R_{\min }$ is a purely numerical parameter defined by computational constraints. Seismic moment conservation requires that the total moment summed from sub events equals the moment of the main fault. Two approaches can reach this condition. First, with a given slip distribution function, the seismic moment for each sub event can be assigned as

$$
M_{i}=\frac{M^{t}}{\sum_{i=1}^{N} S_{i}\left(R_{i}\right)},
$$

where $S_{i}(R)$ is the relative slip weight of the $i$ th sub event with size of $R_{i}$. Second, based on the source scaling relation of $M$ (seismic moment) and $\Delta \sigma R^{3}, \Delta \sigma$ is a constant of proportionality related to the stress drop. The actual seismic moment is

$$
M_{o}^{R}=\Delta \sigma \sum_{i=1}^{N} R_{i}^{3}
$$

$\Delta \sigma$ as a free parameter to be adjusted in order to achieve the actual seismic moment $M_{o}^{R}=M^{t}$ (target total moment).

The source time function for each sub event was determined from its size as

$$
\begin{gathered}
\dot{S}_{i}(t)=\Delta U_{i}\left(2 \pi f_{c}^{i}\right)^{2} t \exp \left(-2 \pi f_{c}^{i} t\right) H(t), \\
f_{c}^{i}=K \frac{\beta}{R_{i}} \\
\Delta U_{i}=C \frac{\Delta \sigma}{\mu} R_{i}
\end{gathered}
$$

where $\dot{S}_{i}(t)$ is the time derivative of source slip function, $t$ is time after the sub event is triggered, $H(t)$ is the Heaviside step function, $\Delta U_{i}$ is mean slip of the $i$ th sub event, $\mu$ is the shear modulus, $\beta$ is the shear-wave velocity, and $C$ is a constant that depends on the geometry of the rupture. The corner frequency, $f_{c}$, has been related to the source characteristic dimension $R_{i}$ of the $i$ th event. The value of $K$ depends on the rupture velocity and rise time and is arbitrarily defined [48].

The resulting ground motion prediction is

$$
U(t)=\sum_{i=1}^{N} \dot{S}_{i}(t) * G_{i}\left(t-t_{i}\right) .
$$

The rupture time, $t_{i}$, was determined using a constant rupture velocity of $2.8 \mathrm{~km} / \mathrm{s}$, corresponding to 85 percent of the shear-wave velocity, and $G_{i}(t)$ is a theoretical Green's function, denoting the ground displacement caused by a unit dislocation on the ith subfault. For the Green's function synthetic computation, a generalized reflection and transmission coefficient matrix method developed by Luco and Apsel [53] and coded by Zeng and Anderson [54] was used to compute elastic wave propagation in a layered elastic halfspace in frequency/wavenumber domain. The generalized reflection and transmission coefficient matrix method is advantageous in the synthetic seismogram computation because it is based on solving the elastodynamic equation complying with the boundary conditions of the free surface, bonded motion at infinity, and continuity of the wave field across each interface.

\section{Results}

As shown in Figure 1, the West Qingling North Boundary Fault Zone (WQNBFZ) cut through Tianshui. Figure 5 shows the segments of WQNBFZ underneath Tianshui: Gangu-Wushan and Tianshui-Baoji Faults. Geologic investigations revealed that the length of the Gangu-Wushan fault segment is about $75 \mathrm{~km}$, and that it has an average leftlateral strike-slip rate of about $2.8 \mathrm{~mm} / \mathrm{y}[1,55]$. The length of the Tianshui-Baoji fault segment is about $150 \mathrm{~km}[1,55]$. The highest intensity (X-XI) in the Tianshui area resulted from the earthquake of $734 \mathrm{AD}$ on the Gangu-Wushan fault segment (Figure 5) [1]. The 734 AD Tianshui earthquake destroyed the City of Tianshui [1]. According to Wells and Coppersmith [56], the Gangu-Wushan fault segment is cable of producing an earthquake of M7.25, which is similar to the estimate of M7.5 obtained from historical earthquake records by Lei and others [1].

The intensity hazard curves (Figure 6) show that in the Tianshui urban area, the recurrent interval for intensity exceeding VIII is between 600 and 900 years, for intensity exceeding IX is between 1,000 and 1,500 years, which is similar to the estimate of M7.5 obtained from historical earthquake records by Lei and others [1]. The recurrence interval for a large earthquake $(\sim \mathrm{M} 7.5)$ along the GanguWushan fault segment was estimated from geologic investigations to be about 2,000 years $[1,55]$. The magnitude and recurrence interval of a large earthquake determined from historical records are quite similar to those determined from geologic investigations. Thus, an M7.5 earthquake, similar to the $734 \mathrm{AD}$ event, was chosen as the scenario event that could have the greatest impact on the Tianshui area.

The composite source model [41] was used to generate synthetic ground motions at grid points with $0.2^{\circ}$ spacing for the scenario earthquake (M7.5). The crustal velocity structure used in the composite model is listed in Table 1 [58-60]. The seismic moment $M_{0}$ in dyn-cm for the scenario earthquake (M7.5) was calculated from Kanamori [61]:

$$
M_{w}=\frac{\log M_{0}}{1.5}-10.73,
$$

to be $2.21 \times 10^{27} \mathrm{dyn}-\mathrm{cm}$. The faults along the WQNBFZ typically dip between 67 and $70^{\circ}$ and have $0^{\circ}$ rake $[1,55]$. 


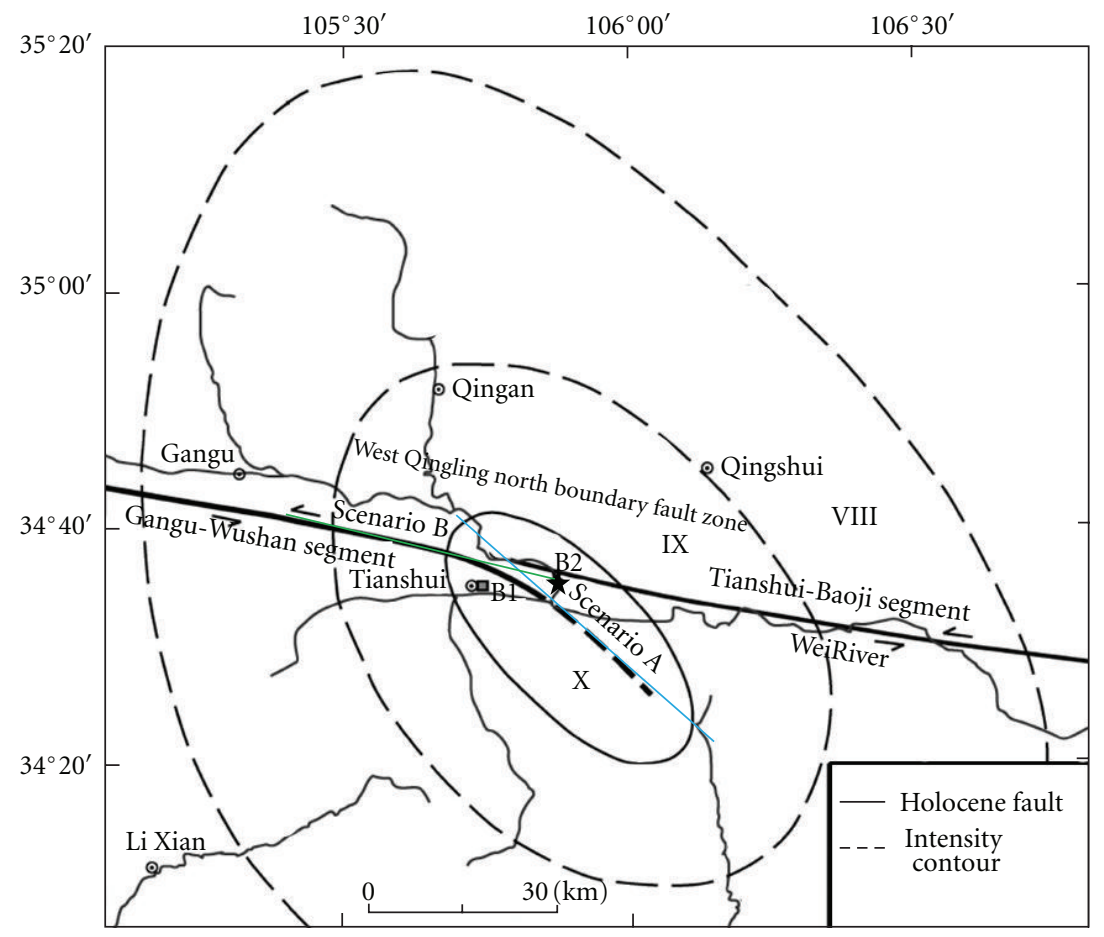

Figure 5: Gangu-Wushan and Tianshui-Baoji faults and scenario earthquake for Tianshui.

TABLe 1: Crustal velocity structure in the Tianshui area.

\begin{tabular}{|c|c|c|c|c|c|c|}
\hline Layer & Thickness $^{1}(\mathrm{~km})$ & $V_{P}^{1}(\mathrm{~km} / \mathrm{s})$ & $Q_{P}{ }^{2}$ & $V_{S}^{1}(\mathrm{~km} / \mathrm{s})$ & $Q_{S}^{2}$ & $\operatorname{Density}^{3}\left(\mathrm{~g} / \mathrm{cm}^{3}\right)$ \\
\hline 1 & 0.25 & 3.9 & 123 & 1.4 & 36.9 & 2.58 \\
\hline 2 & 12.5 & 5.95 & 389 & 3.5 & 194.5 & 2.76 \\
\hline 3 & 11 & 6.2 & 510 & 3.6 & 255 & 2.84 \\
\hline 4 & 11 & 6.4 & 480 & 3.7 & 240 & 2.84 \\
\hline 5 & 7.5 & 6.5 & 550 & 3.75 & 275 & 2.97 \\
\hline 6 & 13 & 6.75 & 550 & 3.88 & 275 & 2.97 \\
\hline 7 & $90^{4}$ & 8 & 550 & 4.55 & 275 & 3.40 \\
\hline
\end{tabular}

${ }^{1} V_{P}$-layer's P-wave velocity, $V_{S}$-layer's S-wave velocity.

${ }^{2} Q_{P}$-layer's P-wave quality factor, $Q_{S}$ - layer's $S$-wave quality factor.

${ }^{3}$ Density-layer's density.

${ }^{4}$ Mantle (half-space).

Therefore, a dip of $68^{\circ}$ and rake of $0^{\circ}$ were used for scenario ground motion simulations. Fault plane geometries were determined using Wells and Coppersmith's [56] empirical relationships for source parameters. Stress drop, $\Delta \sigma$, was calculated using the following expression:

$$
\Delta \sigma=\frac{2}{\pi} \frac{M_{o}}{W^{2} L},
$$

where $W$ is fault width, and $L$ is fault length [62]. The fault rupture velocity for each scenario used 80 percent of the shear velocity.

The composite model for each scenario produced threecomponent ground motion time histories at all grid points. Because location of the 734 AD Tianshui earthquake is not well known, we considered two fault locations, A and $\mathrm{B}$, for scenario ground motion simulation (Figure 5). The source parameters for fault scenarios $\mathrm{A}$ and $\mathrm{B}$ are listed in Tables 2 and 3. For each scenario, ground motion accelerations on bedrock were produced. Figure 7 shows the acceleration time histories for the scenario fault $\mathrm{B}$ at the Tianshui (B1).

The peak values at all grid points were obtained and used to contour the intensity distribution for each scenario ground motion simulation. The intensity scale for peak ground acceleration of Li and others [57] was used to convert peak ground acceleration to the Chinese intensity (Table 4). Figure 8 shows the intensity distributions of historical observations [1] and fault scenario A.

\section{Conclusion}

Recent earthquakes, particularly the 2008 Wenchuan earthquake (M7.9), the 2009 L'Aquila earthquake (M6.3), 


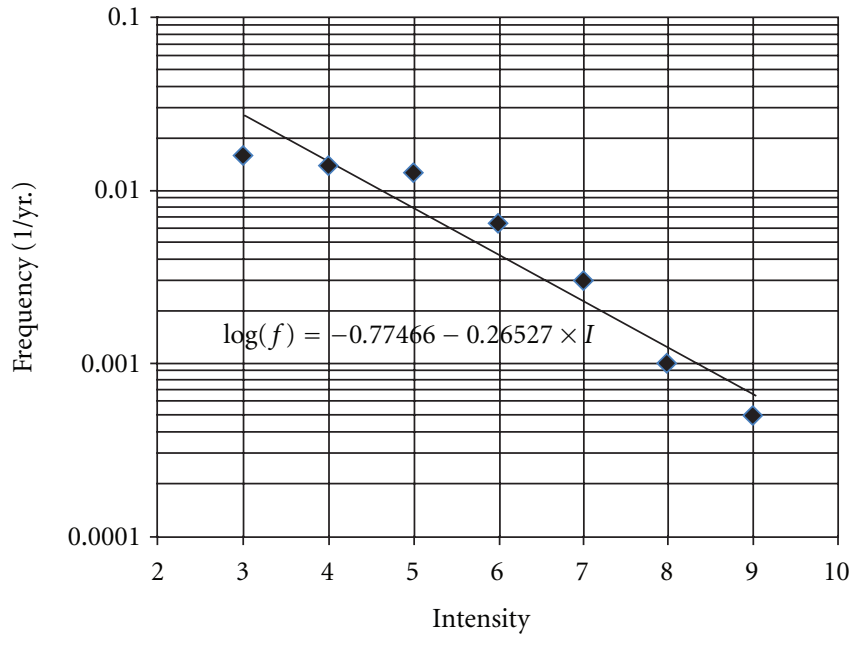

(a)

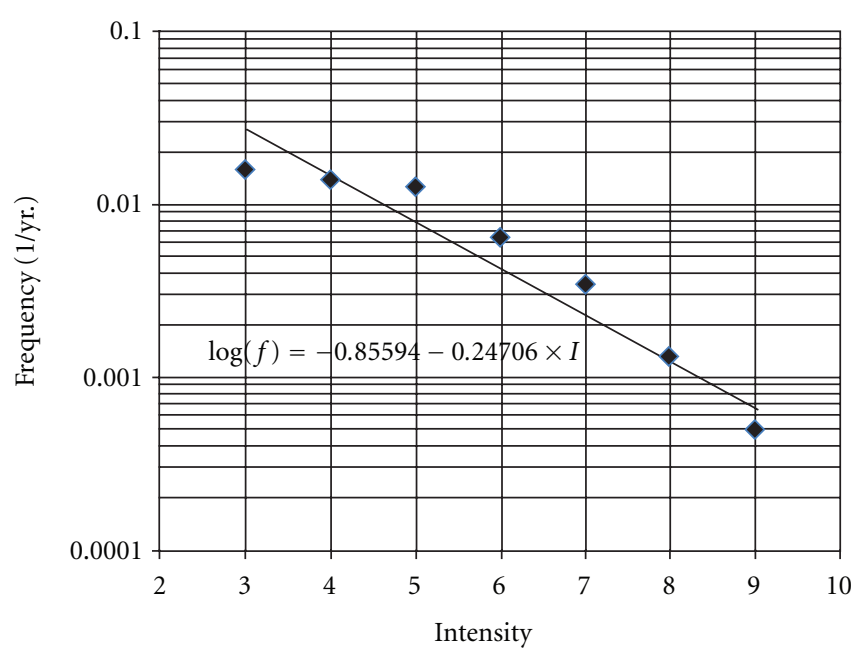

(b)

Figure 6: Intensity hazard curves in Tianshui urban area. (a) At Site B1 and (b) at Site B2 in Figure 5.

TABLE 2: Source parameters for scenario A.

\begin{tabular}{lc}
\hline Parameter & Value \\
\hline Seismic moment & $2.21 \times 10^{27} \mathrm{dyn}-\mathrm{cm}$ \\
Stress drop & $50.72 \mathrm{bars}$ \\
Length of fault plane & $60 \mathrm{~km}$ \\
Width of fault plane & $21.5 \mathrm{~km}$ \\
Epicentral location & $34.529^{\circ} / 105.786^{\circ}$ \\
Hypocentral depth & $19.93 \mathrm{~km}$ \\
Maximum subevent radius & $5.25 \mathrm{~km}$ \\
Minimum subevent radius & $0.5 \mathrm{~km}$ \\
Dip of fault plane & $68^{\circ}$ \\
Strike of fault plane & $128^{\circ}$ \\
Rupture velocity & $2.8 \mathrm{~km} / \mathrm{s}$ \\
Rake & $0^{\circ}$ \\
\hline
\end{tabular}

TABLE 3: Source parameters for scenario B.

\begin{tabular}{lc}
\hline Parameter & Value \\
\hline Seismic moment & $2.21 \times 10^{27} \mathrm{dyn}-\mathrm{cm}$ \\
Stress drop & $39 \mathrm{bars}$ \\
Length of fault plane & $46 \mathrm{~km}$ \\
Width of fault plane & $28 \mathrm{~km}$ \\
Epicentral location & $34.666^{\circ} / 105.713^{\circ}$ \\
Hypocentral depth & $13 \mathrm{~km}$ \\
Maximum subevent radius & $7.0 \mathrm{~km}$ \\
Minimum subevent radius & $0.5 \mathrm{~km}$ \\
Dip of fault plane & $68^{\circ}$ \\
Strike of fault plane & $285^{\circ}$ \\
Rupture velocity & $2.9 \mathrm{~km} / \mathrm{s}$ \\
Rake & $0^{\circ}$ \\
\hline
\end{tabular}

the 2010 Haiti (M7.1) and Chile earthquakes (M8.8), and the 2011 Christchurch (M6.1) and Japan earthquakes
Table 4: The Chinese seismic intensity scale for peak ground acceleration [57].

\begin{tabular}{lc}
\hline Chinese intensity value & Peak ground acceleration \\
\hline VI & $0.05-0.09 \mathrm{~g}$ \\
VII & $0.09-0.18 \mathrm{~g}$ \\
VIII & $0.18-0.36 \mathrm{~g}$ \\
IX & $0.36-0.72 \mathrm{~g}$ \\
$\geq \mathrm{X}$ & $\geq 0.72 \mathrm{~g}$ \\
\hline
\end{tabular}
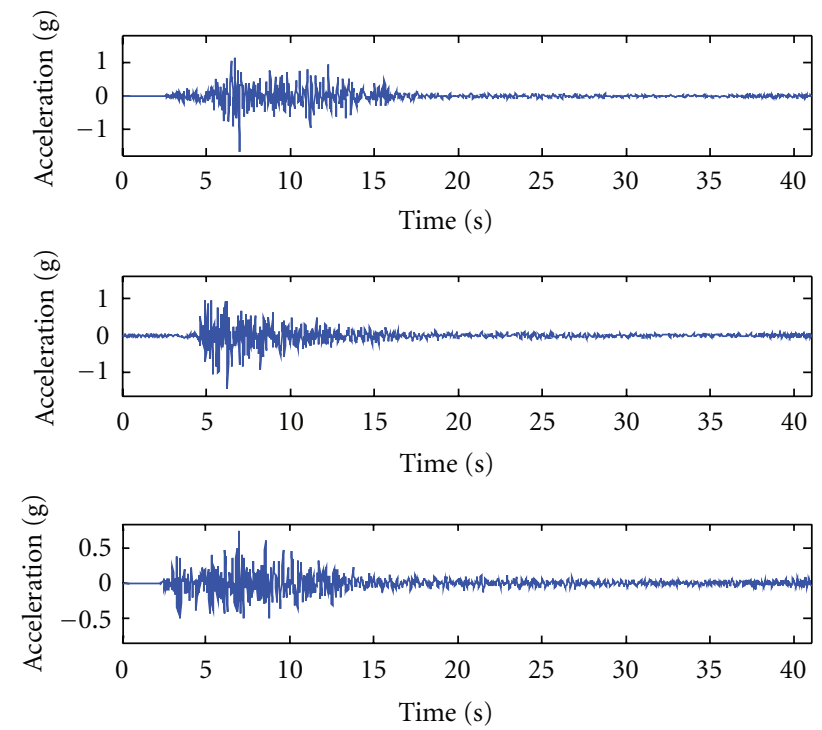

Figure 7: Acceleration time histories at Tianshui (B1) from scenario B.

(M9.0), showed that mitigations-better seismic design for buildings, bridges, and other infrastructure-are the most effective way to reduce seismic risk and avoid earthquake disasters. Although development of policy for seismic hazard 


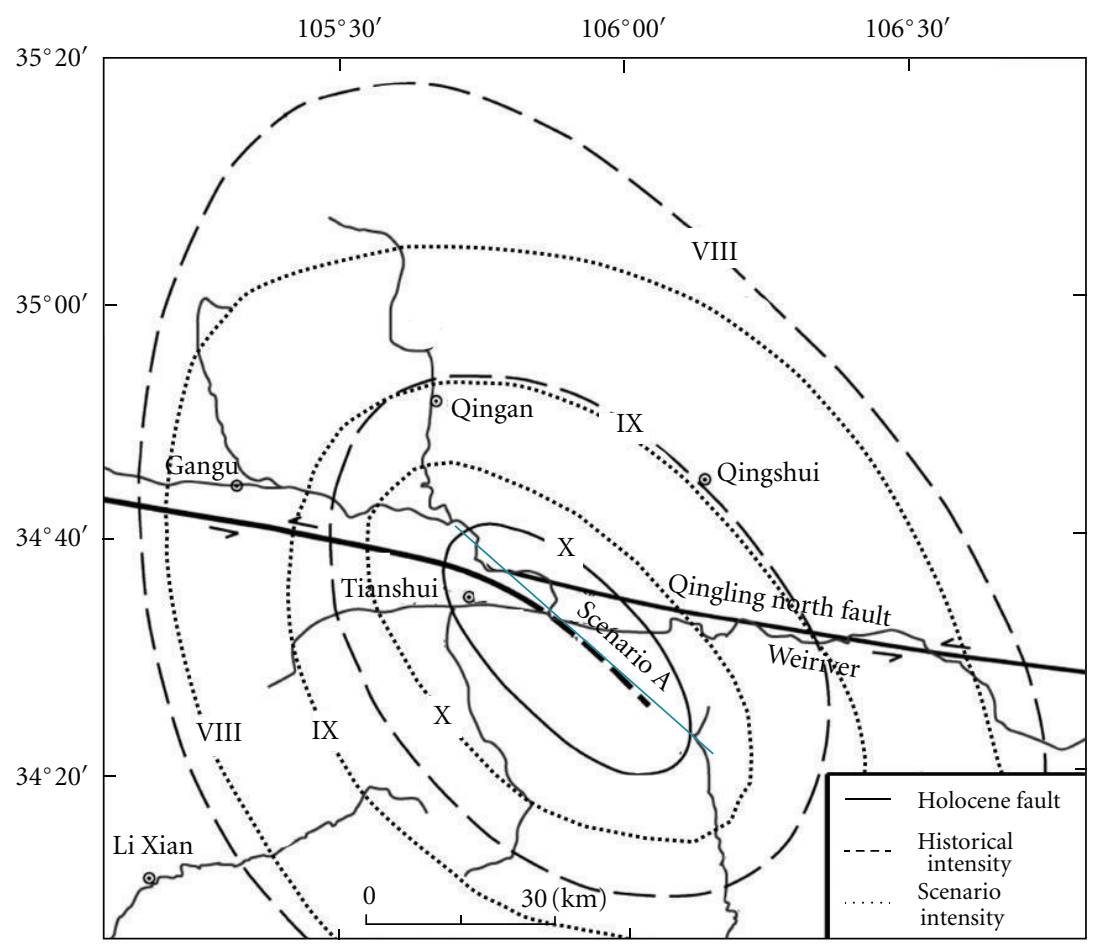

FIGURE 8: Intensity distribution from historical observations [1] and simulation for the scenario A.

mitigation and risk reduction is complex, it starts with seismic hazard assessment; seismic hazard maps. The aim of a seismic hazard assessment is to determine a level of hazard, ground motion in particular, with a frequency of occurrence at a site and the associated uncertainty using the scientific information obtained from instrumental, historical, and geologic observations and research. Thus, earth scientists, seismologists in particular, play key role in seismic hazard assessment.

In this study, we applied a scenario seismic hazard analysis to determine the ground motion hazard in Tianshui area utilizing rich instrumental, historical, and geological data and advanced ground motion modeling. We first derived seismic hazard curves in terms of intensity versus exceedance frequency (per year) from the historical intensity data. In combination with the geological data, then, we determined the scenario earthquakes. Synthetic ground motion time histories on rock were then produced by using the composite source model [41]. Finally, peak ground accelerations (PGAs) and other ground motion parameters are extracted from the synthetic ground motion time histories. The time histories were also used to study site response in the Tianshui area [42].

Although earthquakes from surrounding areas will have an impact on the city of Tianshui, the earthquakes along the West Qinling north boundary fault zone, particularly the Gangu-Wushan fault segment, will have the most significant impact. The highest intensity (Chinese Seismic Intensity Scale) experienced in Tainshui area (X) resulted from the M7.5 earthquake (M7.5) of $734 \mathrm{AD}$ that occurred on the
TABLE 5: Recommended design parameters for the city of Tianshui.

\begin{tabular}{lccc}
\hline Recurrence interval (years) & 500 & 1,000 & 2,500 \\
Chinese intensity & VIII & VIII & $\geq$ IX \\
Equivalent PGA $(\mathrm{g})$ & 0.20 & 0.30 & $\geq 0.40$ \\
\hline
\end{tabular}

Gangu-Wushan segment of WQNBFZ. Geologic investigation revealed that the length of the Gangu-Wushan fault segment is about $75 \mathrm{~km}$ and has an average left-lateral strikeslip rate of about $2.0 \mathrm{~mm} / \mathrm{yr}$. The recurrence interval for large earthquake (M7.5) along the Gangu-Wushan fault segment was estimated from geologic investigations to be about 2,000 years. Intensity data analysis shows that the recurrence interval in the Tianshui area for intensity exceeding VIII is between 600 and 900 years, for intensity exceeding IX is between 1,000 and1,500 years, and for intensity exceeding $\mathrm{X}$ is greater than 2,000 years.

The parameters shown in Table 5 are recommended for engineering design and other mitigation considerations in the Tianshui area.

\section{Acknowledgments}

The financial support for this project was partly provided by the reconstruction founds for Wenchuan earthquake hit area of Gansu province, China State Administration of Foreign Experts Affairs, and Gansu Provincial Administration of Foreign Experts Affairs. The authors would like to thank the staff at LIS, especially Dr. Yucheng Shi, Dr. Zhongxia Yuan, Dr. 
Zhijian Wu, Miss Haimei Sun, and Miss Yuxia Lu. They wish to offer special thanks Jingwei Liu for invaluable support in the creation of the earthquake database. They appreciate the three reviewers for their constructive comments and suggestions which helped to improve this paper greatly. They also thank Meg Smath of Kentucky Geological Survey for editorial help.

\section{References}

[1] Z. S. Lei, D. Y. Yuan, W. P. Ge, W. G. He, and X. W. Liu, "Textual research on the Tianshui M 7 earthquake in $734 \mathrm{AD}$ and analysis of its causative structure," Dizhen Dizhi, vol. 29, no. 1, pp. 51-62, 2007 (Chinese).

[2] F. Xie, Z. Wang, Y. Du, and X. Zhang, "Preliminary observations of the faulting and damage pattern of M8. 0 Wenchuan, China, earthquake," The Professional Geologist, vol. 46, pp. 3-6, 2009.

[3] Building Seismic Safety Council (BSSC), NEHRP Recommended Provisions for Seismic Regulations for New Buildings, Federal Emergency Management Agency, 2009.

[4] M. D. Petersen, A. D. Frankel, S. C. Harmsen et al., "Documentation for the 2008 update of the United States national seismic hazard maps," Tech. Rep. 08-1128, U.S. Geological Survey Open-File Report, 2008.

[5] International Building Code Council (IBCC), International building code: 678 p., 2010.

[6] People's Republic of China National Standard (PRCNS), Seismic Ground Motion Parameter Zonation Map of China, GB 18306-2001, China Standard Press, 2001.

[7] M. Stucchi, C. Meletti, V. Montaldo, H. Crowley, G. M. Calvi, and E. Boschi, "Seismic hazard assessment (2003-2009) for the Italian building code," Bulletin of the Seismological Society of America, vol. 101, no. 4, pp. 1885-1911, 2011.

[8] C. A. Cornell, "Engineering seismic risk analysis," Bulletin of the Seismological Society of America, vol. 58, pp. 1583-1606, 1968.

[9] E. L. Krinitzsky, "Deterministic versus probabilistic seismic hazard analysis for critical structures," Engineering Geology, vol. 40, no. 1-2, pp. 1-7, 1995.

[10] E. L. Krinitzsky, "How to obtain earthquake ground motions for engineering design," Engineering Geology, vol. 65, no. 1, pp. $1-16,2002$.

[11] T. C. Hanks, "Imperfect science: uncertainty, diversity, and experts," Eos, vol. 78, no. 35, pp. 369-377, 1997.

[12] J. J. Bommer and N. A. Abrahamson, "Reply to "Comment on 'Why do modern probabilistic seismic-hazard analyses often lead to increased hazard estimates?' by Julian J. Bommer and Norman A. Abrahamson" by Zhenming Wang and Mai Zhou," Bulletin of the Seismological Society of America, vol. 97, no. 6, pp. 2215-2217, 2007.

[13] Z. Wang, "Comment on "Sigma: Issues, insights, and challenges” by F. O. Strasser, N. A. Abrahamson J. J. Bommer," Seismological Research Letters, vol. 80, no. 3, pp. 491-493, 2009.

[14] Z. Wang, "Seismic hazard assessment: issues and alternatives," Pure and Applied Geophysics, vol. 168, no. 1-2, pp. 11-25, 2011.

[15] Z. Wang and C. Cobb, "A critque of probablistic versus deterministic seismic hazard analysis with special reference to the New Mardid seismic zone," in Recent Advances in North American Paleoseismology and Neotectonics East of Rockies: Geological Society of America Special Paper 493, R. T. Cox, M. P. Tuttle, O. S. Boyd, and J. Locat, Eds., p. 17, 2012.
[16] J. G. Anderson and J. N. Brune, "Probabilistic seismic hazard analysis without the ergodic assumption," Seismological Research Letters, vol. 70, no. 1, pp. 19-28, 1999.

[17] Z. Wang, "Comment on "PSHA Validated by Quasi Observational Means" by R. M. W. Musson," Seismological Research Letters, vol. 83, pp. 714-716, 2012.

[18] T. C. Hanks, "Extreme ground motions," in Annual Meeting of the Seismological Society of America, Memphis, Tenn, USA, April 2011.

[19] F. Scherbaum and N. Kuehn, "Logic tree branch weights and probabilities: summing up to one is not enough," Earthquake Spectra, vol. 27, pp. 1237-1251, 2011.

[20] F. . Scherbaum and N. Kuehn, "Capturing epistemic uncertainties in PSHA within a logic tree framework (abstract): the 2012," in Annual Meeting of the Seismological Society of America, pp. 17-19, San Diego, Calif, USA, April 2012.

[21] R. M. W. Musson, "PSHA validated by quasi observational means," Seismological Research Letters, vol. 83, no. 1, pp. 130$134,2012$.

[22] R. M. W. Musson, "Probability in PSHA: reply to 'Comment on 'PSHA Validated by Quasi-Observational Means' by Z. gg'” Seismological Research Letters, vol. 83, pp. 717-719, 2012.

[23] Z. Wang and M. Lu, "A short note on ground-motion recordings from the M 7.9 Wenchuan, China, earthquake and ground-motion prediction equations in the Central and Eastern United States," Seismological Research Letters, vol. 82, no. 5, pp. 731-734, 2011.

[24] R. J. Geller, "Shake-up time for Japanese seismology," Nature, vol. 472, no. 7344, pp. 407-409, 2011.

[25] S. Stein, R. J. Geller, and M. Liu, "Bad assumptions or bad luck: why earthquake hazard maps need objective testing," Seismological Research Letters, vol. 82, pp. 623-626, 2011.

[26] S. Stein, R. J. Geller, and M. Liu, "Why earthquake hazard maps often fail and what to do about it," Tectonophysics, vol. 562-563, pp. 1-25, 2012.

[27] V. G. Kossobokov and A. K. Nekrasova, "Global seismic hazard assessment program maps are erroneous," Seismic Instruments, vol. 48, no. 2, pp. 162-170, 2012.

[28] J. C. Stepp, I. Wong, J. Whitney et al., "Probabilistic seismic hazard analyses for ground motions and fault displacement at Yucca Mountain, Nevada," Earthquake Spectra, vol. 17, no. 1, pp. 113-151, 2001.

[29] R. Street, Z. Wang, I. Harik, and D. Allen, "Source zones, recurrence rates, and time histories for earthquakes affecting kentucky," Research Report KCT-96-4, University of Kentucky, Kentucky Transportation Center, 1996.

[30] G. F. Panza, F. Romanelli, and F. Vaccari, "Seismic wave propagation in laterally heterogeneous anelastic media: theory and applications to seismic zonation," Advances in Geophysics, vol. 43, pp. 1-95, 2001.

[31] Z. Wang, E. W. Woolery, B. Shi, and I. E. Harik, "Seismic hazard maps and time histories from earthquakes affecting Kentucky," Research Report KTC-07-06/SPR246-02-6F, University of Kentucky, Kentucky Transportation Center, 2007.

[32] K. Irikura and H. Miyake, "Recipe for predicting strong ground motion from crustal earthquake scenarios," Pure and Applied Geophysics, vol. 168, no. 1-2, pp. 85-104, 2011.

[33] E. Zuccolo, F. Vaccari, A. Peresan, and G. F. Panza, "Neodeterministic and probabilistic seismic hazard assessments: a comparison over the Italian territory," Pure and Applied Geophysics, vol. 168, no. 1-2, pp. 69-83, 2011.

[34] L. Reiter, Earthquake Hazard Analysis, Columbia University Press, New York, NY, USA, 1990. 
[35] C. H. Cramer, "Comment on 'communicating with uncertainty: a critical issue with probabilistic seismic hazard analysis," Eos, vol. 85, no. 30, p. 283, 2004.

[36] L. Mualchin, "History of modern earthquake hazard mapping and assessment in California using a deterministic or scenario approach," Pure and Applied Geophysics, vol. 168, no. 3-4, pp. 383-407, 2011.

[37] NCh433.Of96, Earthquake Resistant Design of Buildings, Official Chilean Code, Santiago, Chile, 1996.

[38] H. Kuramoto, "Seismic design codes for buildings in Japan," Journal of Disaster Research, vol. 1, pp. 341-356, 2006.

[39] J. W. Liu, Z. M. Wang, and F. R. Xie, "Seismic hazard and risk assessments for Beijing-Tianjin-Tangshan area, China," Chinese Journal of Geophysics, vol. 53, no. 2, pp. 318-325, 2010 (Chinese).

[40] F. Xie, Z. Wang, and J. Liu, "Seismic hazard and risk assessments for Beijing-Tianjin-Tangshan, China, area," Pure and Applied Geophysics, vol. 168, no. 3-4, pp. 731-738, 2011.

[41] Yuehua Zeng, J. G. Anderson, and Guang Yu, "A composite source model for computing realistic synthetic strong ground motions," Geophysical Research Letters, vol. 21, no. 8, pp. 725$728,1994$.

[42] T. D. Butler III, Scenario hazard assessment of Tianshui's urban area, Gansu Province, People's Republic of China [M.S. thesis], University of Kentucky, 2011.

[43] S. B. Bozkurt, R. S. Stein, and S. Toda, "Forecasting probabilistic seismic shaking for greater Tokyo from 400 years of intensity observations," Earthquake Spectra, vol. 23, no. 3, pp. 525-546, 2007.

[44] State Seismological Bureau (SSB), Disaster Prevention Department, Catalogue of Chinese Historical Strong Earthquakes, Earthquake Publishing House, Beijing, China, 1995.

[45] C. E. A. China Earthquake Administration (), Recent Earthquake Catalogue of China (1912-1990, $M_{S} \geq 4.7$, Chinese Science and Technology Press., Beijing, China, 2000.

[46] S. Wang, Y. Yu, A. Gao, and X. Yan, "Development of attenuation relations for ground motion in China," Earthquake Research in China, vol. 16, pp. 99-106, 2000 (Chinese).

[47] D. M. Boore and G. M. Atkinson, "Stochastic prediction of ground motion and spectral response parameters at hard-rock sites in Eastern North America," Bulletin of the Seismological Society of America, vol. 77, pp. 440-467, 1987.

[48] I. A. Beresnev and G. M. Atkinson, "Modeling finite-fault radiation from the $\omega$ n spectrum," Bulletin of the Seismological Society of America, vol. 87, no. 1, pp. 67-84, 1997.

[49] P. Somerville, M. Sen, and B. Cohee, "Simulation of strong ground motions recorded during the 1985 Michoacan, Mexico and Valparaiso, Chile earthquakes," Bulletin of the Seismological Society of America, vol. 81, no. 1, pp. 1-27, 1991.

[50] B. Shi, Z. Wang, and E. W. Woolery, Source Scalling, Subevent Distributions, and Ground-Motion Simulation in the Composite Source Model. Report of Investigations, Kentucky Geological Survey, series 12, 2006.

[51] R. W. Graves, "Simulating seismic wave propagation in 3D elastic media using staggered-grid finite differences," Bulletin of the Seismological Society of America, vol. 86, no. 4, pp. 10911106, 1996.

[52] K. A. Macpherson, E. W. Woolery, Z. Wang, and P. Liu, "Three-dimensional long-period groundmotion simulations in the upper Mississippi embayment," Seismological Research Letters, vol. 81, no. 2, pp. 391-405, 2010.

[53] J. E. Luco and R. J. Apsel, “On the Green's function for a layered half space," Bulletin of Seismological Society of America, vol. 73, pp. 909-929, 1983.
[54] Y. Zeng and J. G. Anderson, "A method for direct computation of the differential seismogram with respect to the velocity change in a layered elastic solid," Bulletin of the Seismological Society of America, vol. 85, no. 1, pp. 300-307, 1995.

[55] Z. C. Wang, P. Z. Zhang, G. L. Zhang et al., "Tertiary tectonic activities of the north frontal fault zone of the west Qinling mountains: implications for the growth of the northeastern margin of the Qinghai-Tibetan plateau," Earth Science Frontiers, vol. 13, pp. 119-135, 2006.

[56] D. L. Wells and K. J. Coppersmith, "New empirical relationships among magnitude, rupture length, rupture width, rupture area, and surface displacement," Bulletin of the Seismological Society of America, vol. 84, no. 4, pp. 974-1002, 1994.

[57] X. Li, Z. Zhou, H. Yu et al., "Strong motion observations and recordings from the great Wenchuan Earthquake," Earthquake Engineering and Engineering Vibration, vol. 7, no. 3, pp. 235246, 2008.

[58] M. Zhou, Y. Zhang, Q. Li, and B. Fan, "Q-structure in Tianshui earthquake area," Acta Geophysica Sinica, vol. 39, supplement, pp. 216-222, 1996 (Chinese).

[59] M. Liu, W. D. Mooney, S. Li, N. Okaya, and S. Detweiler, "Crustal structure of the northeastern margin of the Tibetan plateau from the Songpan-Ganzi terrane to the Ordos basin," Tectonophysics, vol. 420, no. 1-2, pp. 253-266, 2006.

[60] J. Zhang, R. Gao, L. Zeng et al., "Relationship between crustal $3 \mathrm{D}$ sensity structure and the earthquakes in the Longmenshan Range and adjacent areas," Acta Geologica Sinica, vol. 83, pp. 740-745, 2009.

[61] H. Kanamori, "The energy release in great earthquakes," Journal of Geophysical Research, vol. 82, pp. 1981-2987, 1977.

[62] S. Stein and M. Wysession, An Introduction to Seismology, Earthquakes and Earth Structure, Blackwell, 2003. 

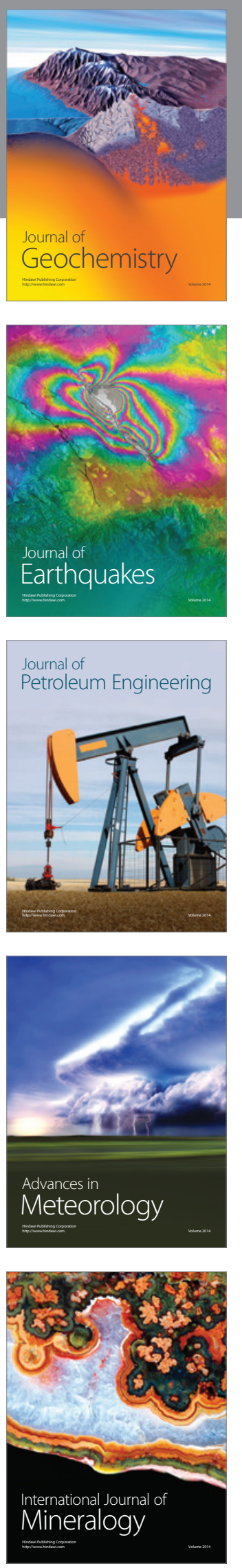
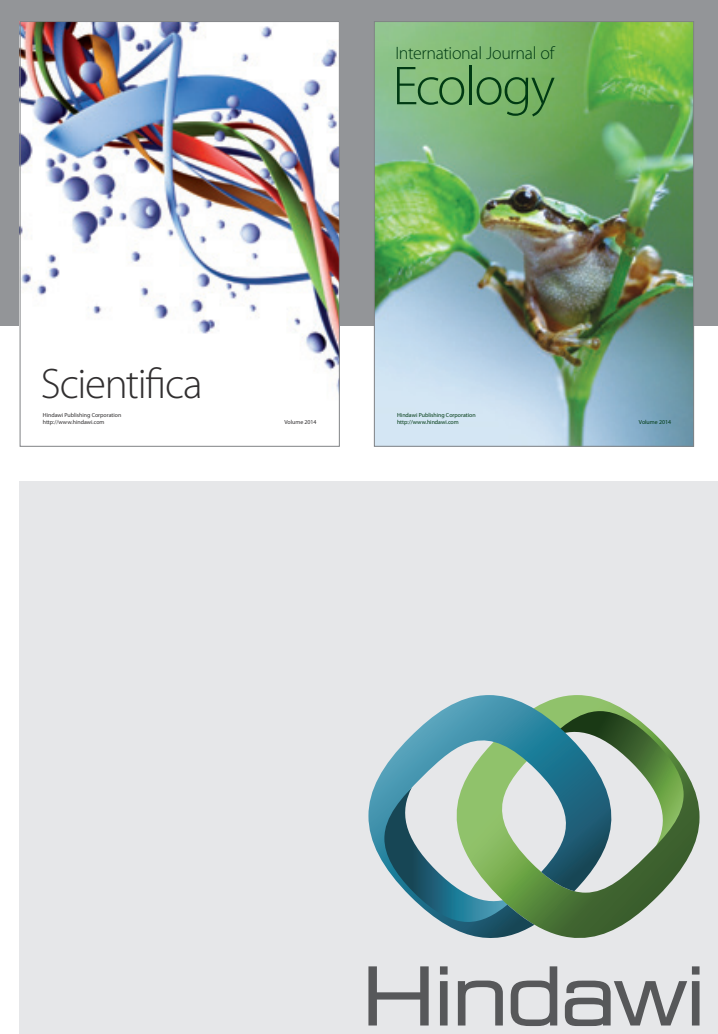

Submit your manuscripts at http://www.hindawi.com
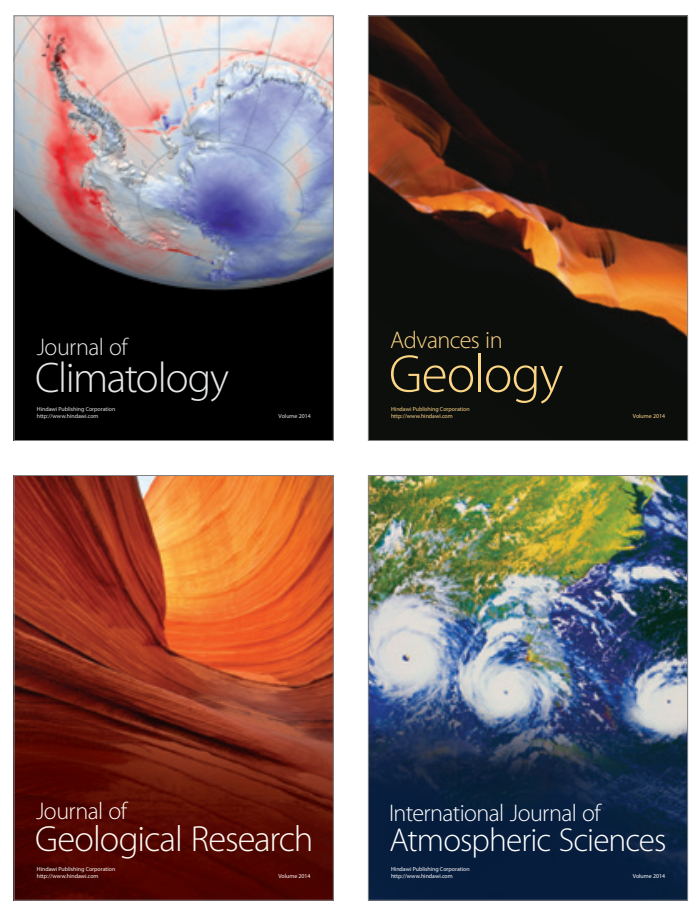
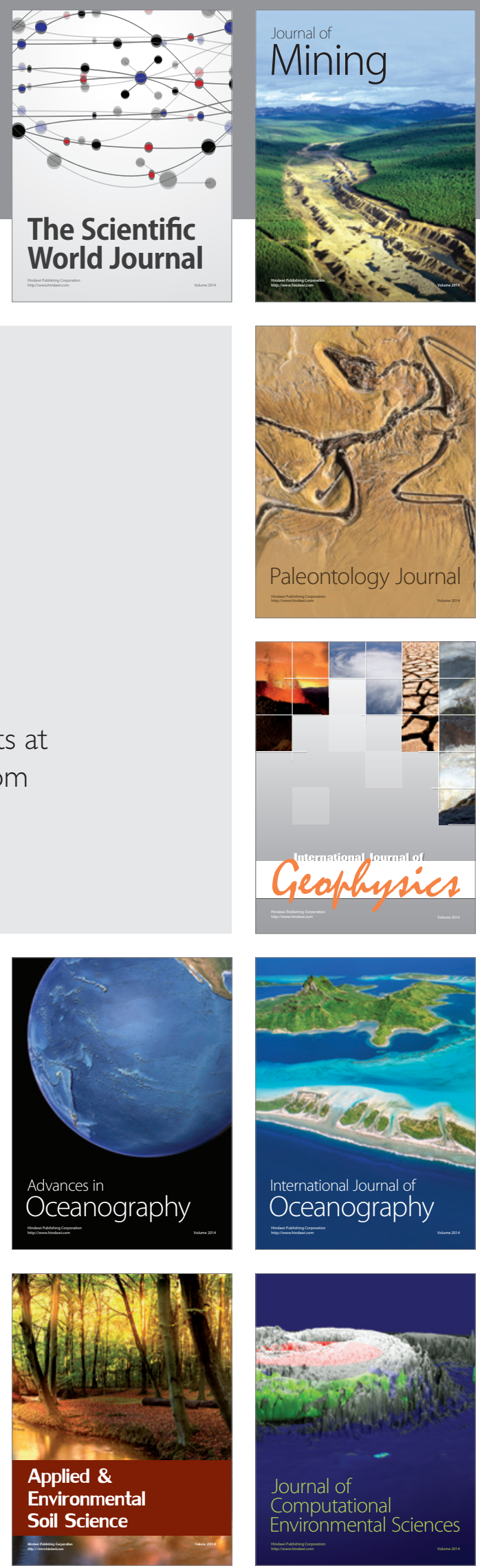